\title{
Caracterización biológica y molecular del aislamiento CIBMUQ/HDC, una cepa colombiana de referencia para Toxoplasma gondii
}

\author{
Carolina Gallego 1, Jhon Carlos Castaño 2, Alejandra Giraldo ${ }^{2}$ Daniel Ajzenberg ${ }^{3}$, \\ Marie-Laure Dardé ${ }^{3}$, Jorge Enrique Gómez ${ }^{1}$ \\ ${ }^{1}$ Grupo de Estudio en Parasitologia Molecular, Centro de Investigaciones Biomédicas, Universidad del \\ Quindio, Armenia, Colombia. \\ ${ }^{2}$ Grupo de Inmunología Molecular, Centro de Investigaciones Biomédicas, Universidad del Quindío, Armenia, \\ Colombia. \\ ${ }^{3}$ Laboratoire de Parasitologie-Mycologie, EA3174, Faculté de Médecine, 2 rue du docteur Marcland, \\ 87031 Limoges, France.
}

Existen pocos datos sobre la caracterización de cepas de Toxoplasma gondii que analicen las diferencias entre las cepas aisladas de casos humanos en Europa y Estados Unidos con cepas aisladas en Suramérica. Este trabajo presenta los resultados de la caracterización biológica basada en cultivo in vitro y análisis de virulencia en ratón, y la caracterización molecular obtenida por la amplificación del gen multicopia específico de T. gondii (B1), la genotipificación por PCR-RFLP del gen que codifica para el antígeno de membrana SAG2 y el análisis por microsatélites de un aislamiento clínico de toxoplasmosis congénita ocurrido en Armenia (Colombia). El análisis de virulencia en ratón demostró que esta cepa tenía una $\mathrm{DL}_{100}$ de 10 taquizoítos. La genotipificación y el análisis por microsatélites demostraron que esta cepa pertenecía al tipo clonal 1 y se denominó HOM/CTCO/2002/CIBMUQ/BL/HDC (nombre abreviado: CIBMUQ/HDC). CIBMUQ/HDC se encuentra disponible como cepa de referencia del país para estudios tanto a nivel nacional como internacional.

Palabras clave: Toxoplasma, cepas, virulencia, toxoplasmosis congénita.

Molecular and biological characterization of the CIBMUQ/HDC strain, a reference strain for Colombian Toxoplasma gondii

There are few reports about characterization strains of Toxoplasma gondii that analyze the differences between isolates from Europe or United States with those obtained in South America. The current study analyzes virulence data from the mouse model, the gene SAG2 polymorphism by PCR-RFLP and microsatellite analysis in a single Colombian isolate. The strain was isolated from blood of a child with congenital toxoplasmosis, living in Armenia, Colombia. Analysis of virulence in the mouse showed that this strain has an $L D_{100}$ of 10 tachyzoites. Both methods of genetic characterization demonstrated that this strain belonged to the clonal type 1 and was called HOM/CTCO/2002/CIBMUQ/BL/HDC (brief name: CIBMUQ/HDC). The CIBMUQ/HDC strain is the first Colombian strain available as a reference strain for national and international researchers.

Key words: Toxoplasma, strains, virulence, congenital toxoplasmosis.

Correspondencia:

Jorge Enrique Gómez, Centro de investigaciones Biomédicas, Universidad del Quindío, Carrera 15 con calle 12 N, Armenia, Quindío, Colombia.

Teléfono/fax: (576) 7460168

gepamol@uniquindio.edu.co

Recibido: 13/05/04; aceptado: 23/07/04
Toxoplasma gondii es un parásito intracelular obligado cuyos hospederos definitivos son los felinos en los cuales ocurre una fase de reproducción sexuada que genera ooquistes que infectan al hombre y a un amplio espectro de hospederos vertebrados. La transmisión de $T$. gondii al hombre ocurre por la ingestión de 
ooquistes excretados en heces de felinos, por ingestión de quistes tisulares en carne insuficientemente cocida o por transmisión vertical (1). Aunque la infección con este parásito es generalmente asintomática en adultos sanos, es causa importante de morbilidad y mortalidad en pacientes inmunocomprometidos, principalmente, pacientes con sida o con trasplante de órganos y en niños infectados congénitamente $(1,2)$.

La progresión y la gravedad de la enfermedad difieren entre pacientes por variables que incluyen la genética del hospedero y la del parásito $(2,3)$. Es bien conocido que la virulencia de T. gondiien animales difiere dependiendo de la cepa del parásito (4). La identificación de una posible correlación entre la gravedad o el tipo de enfermedad y el genotipo de la cepa podría ser importante para determinar el tratamiento correcto en cada caso humano (5). Las cepas de T. gondii se han subdividido en tres grupos principales usando diferentes métodos de caracterización, como el análisis isoenzimático (zimodemas), la virulencia en el ratón blanco suizo y el análisis de los polimorfismos en los fragmentos de restricción (RFLP) $(2,3,6)$.

Los linajes clonales descritos, llamados tipo I, II y III, corresponden bien con el análisis genético del locus polimórfico del antígeno de superficie SAG2 (3). Las cepas tipo II y III presentan igual prevalencia en animales naturalmente infectados; sin embargo, el genotipo II está asociado con la mayoría de aislamientos humanos (2). En contraste, la virulencia aguda en ratón está restringida a las cepas tipo I $(7,8)$. Las cepas del grupo clonal I, como la RH, muestran una dosis letal 100 de un solo parásito viable, mientras las cepas no virulentas demuestran una dosis letal 50 mayor o igual a 1.000 taquizoítos (9). Estos agrupamientos en linajes clonales se han correlacionado con las diferentes formas clínicas de la toxoplasmosis humana. El tipo I y los clones atípicos están más frecuentemente asociados con casos graves de toxoplasmosis congénita. El tipo II se ha encontrado en $65 \%$ de las cepas aisladas de casos de reactivación en pacientes con sida y el tipo III se ha aislado comúnmente de animales $y$, ocasionalmente, en casos humanos (10). Esta correlación entre linaje y fenotipo sugiere que el genotipo de un parásito determina la severidad y la progresión de la enfermedad (10).

Hasta el presente no se han realizado estudios que analicen las diferencias entre las cepas aisladas en Europa y Estados Unidos con las cepas aisladas de casos humanos en Suramérica. Se ha reportado la existencia de formas clínicas graves e infrecuentes de toxoplasmosis humana en Suramérica, entre ellas, la hidranencefalia que es diferente a la forma conocida de hidrocefalia $(11,12)$ y los brotes de retinocoroiditis adquirida $(13,14)$. Estas formas clínicas no han sido reportadas en otros continentes, así como formas clínicas graves en pacientes inmunocompetentes en Guyana (15). Bridley et al. han hecho la única descripción que existe sobre estas cepas (16); describió una cepa procedente de Brasil (OH3) la cual estaba involucrada en la forma de retinocoroiditis adquirida. Este aislamiento tenía similaridades biológicas con las formas virulentas de T. gondii en ratón e, in vivo, fue menos sensible a la sulfadiazina comparado con la cepa Rh (16). Sibley y Boothroyd hallaron que esta cepa $\mathrm{OH} 3$ pertenecía al clon virulento (7).

A partir de estos hallazgos, se hace importante conocer más sobre la distribución y las características de las cepas virulentas suramericanas. No es claro si la presencia de formas clínicas graves de toxoplasmosis humana en Suramérica es sólo un problema de una mayor frecuencia de la infección o si los clones virulentos para el humano pueden estar más extendidos en en esta región. Por lo tanto, se hace necesario recolectar el mayor número posible de cepas de T. gondii de diferentes áreas geográficas con el fin de analizar la estabilidad espacial y temporal de los clones existentes, lo que podría definir su importancia médica. Como respuesta a este problema se ha emprendido un esfuerzo con el fin de caracterizar cepas colombianas de T. gondii.

Durante la realización de este trabajo se obtuvo un aislamiento que creció rapidamente en cultivo celular y se pudo caracterizar con todos los métodos disponibles. El propósito de este artículo es presentar los resultados de un aislado colombiano de $T$. gondii obtenido de un caso de 
toxoplasmosis humana que fue caracterizado por la técnica de análisis de los polimorfismos del tamaño de los fragmentos de restricción (RFLP) del gen SAG2 y su análisis de marcadores genéticos por microsatélites para establecer su linaje clonal.

\section{Materiales y métodos}

Descripción del caso clínico: el parásito se aisló de un niño de 12 días de nacido. La madre tenía 13 años de edad y era primigestante; en el interrogatorio refirió que había presentado adenopatías y fiebre en el primer mes de embarazo.

Sólo asistió a un control prenatal a la semana 20 de embarazo, momento en el cual se le ordenaron pruebas específicas de anticuerpos para IgG, IgM e IgA de Toxoplasma como parte del programa de tamizaje prenatal para toxoplasmosis realizado por el Centro de Investigaciones Biomédicas y el Instituto Seccional de Salud del Quindío en el 2002. Los resultados de esta pruebas fueron positivos: IgG, $200 \mathrm{UI} / \mathrm{ml}$ (positivo>10 Ul/ml); IgM, 12 puntos por ISAGA (positivo $>5$ puntos), e IgA 12 puntos (positivo $>5$ puntos). La paciente no continuó con el seguimiento por lo cual no se le pudo informar el resultado ni se inició tratamiento durante el embarazo.

La madre presentó un parto pretérmino a las 33 semanas de gestación en el Hospital San Juan de Dios de Armenia. El peso al nacer fue de 1.725 g y la talla de $38 \mathrm{~cm}$; en el examen físico presentó signos sistémicos de infección (ictericia y hepatoesplenomegalia). Como la madre presentó los resultados de los exámenes realizados, el personal del hospital previno al grupo del Centro de Investigaciones Biomédicas y se tomó muestra de sangre periférica del recién nacido para cultivo celular, PCR y determinación de anticuerpos para Toxoplasma. Las pruebas serológicas fueron positivas con un resultado de $10 \mathrm{UI} / \mathrm{ml}$ para IgG por Immulite (positivo>8 UI/ml) y Western blot positivo para IgG (positivo por presencia de bandas específicas).

Se inició tratamiento desde los 12 días de vida con pirimetamina-sulfadoxina a una dosis de 1 $\mathrm{mg} / \mathrm{kg}$ de pirimetamina y $25 \mathrm{mg} / \mathrm{kg}$ de sulfadoxina hasta el primer año de vida.
Obtención del aislamiento clínico: a partir de la muestra de sangre periférica del recién nacido se realizó separación de leucocitos utilizando el método de sedimentación por gradiente con Lymphoprep (Axis-Shield, Noruega) siguiendo las instrucciones del fabricante. Posteriormente, se realizó observación directa del aislamiento en microscopio de luz (400 X) donde se visualizaron formas compatibles con Toxoplasma.

Cultivo celular y cultivo en ratón: la muestra clínica (leucocitos del paciente) se inoculó directa y simultáneamente en frascos de cultivo celular con la línea HT29 en fase de monocapa y por vía intraperitoneal en ratones Balb/C. El aislamiento se mantuvo en cultivo celular y en pase en ratón; se congeló y almacenó a $-70^{\circ} \mathrm{C}$. A partir de este material se realizaron pases sucesivos en ratón.

Cultivo celular: se utilizó la línea celular de carcinoma de colon humano HT29 (ATCC HTB38), mantenida en frascos de cultivo de $25 \mathrm{ml}$ con medio RPMI (Gibco BRL, USA) con suplemento de suero fetal bovino al 10\% (Whitaker, USA) inactivado con calor, más solución de penicilina más estreptomicina y anfotericina $B$ (Sigma, USA). Las células se incubaron a $37^{\circ} \mathrm{C}$ en una atmósfera de $\mathrm{CO}_{2}$ al $5 \%$.

Animales: se emplearon ratones hembra Balb/C para el aislamiento a partir de la muestra del paciente, y ratones ICR exogámicos para la prueba de virulencia de 6 a 8 semanas de edad suministrados por el Bioterio Central de la Universidad Nacional de Colombia. Los animales se sacrificaron por dislocación cervical en el momento de la presentación de síntomas posinoculación como piloerección y ataxia del tren posterior. Se realizó lavado peritoneal con $5 \mathrm{ml}$ de solución salina normal y éste se concentró por centrifugación a $3000 \mathrm{~g}$ por 15 minutos para la recuperación de los parásitos.

Inmunofluorescencia directa: para confirmar que las formas observadas en el cultivo celular eran de $T$. gondii, se realizó una prueba con el anticuerpo monoclonal TgG9 específico contra la proteína de membrana SAG1, según el procedimiento que se describe a continuación. Se fijaron láminas para fluorescencia de 10 pozos con $50 \mathrm{ml}$ de parásitos obtenidos del aislamiento 
clínico a una concentración de $1 \times 10^{6}$ taquizoítos fijados utilizando una solución de acetona fría (1X). A la lámina se adicionaron $50 \mathrm{ml}$ del anticuerpo monoclonal TgG9 contra la proteína SAG1 (17) a una concentración de $100 \mathrm{mg} / \mathrm{ml}$. Las láminas se incubaron 1 hora a $37^{\circ} \mathrm{C}$ en cámara húmeda; se lavaron y se adicionaron $20 \mathrm{ml}$ de una solución de conjugado anti-IgG de ratón obtenido en conejo y marcada con isotiocianato de fluoresceína (Sigma, MO, USA) a una dilución de 1:40 en azul de Evans al $1 \%$. Se realizó la lectura visual en un microscopio de luz ultravioleta Eclipse E-600 (Nikon, USA) con un filtro de absorción de 485 $\mathrm{nm}$ y de emisión de $520 \mathrm{~nm}$. El control negativo fue una lámina en las mismas condiciones omitiendo la adición del anticuerpo monoclonal.

\section{Experimentos de virulencia, determinación de la dosis letal 100 y prueba de estabilidad de la virulencia: se utilizaron tres grupos de ratones ICR cada uno con tres individuos. Cada grupo fue inoculado por vía intraperitoneal con una cantidad diferente de parásitos: $10,1.000$ y 500.000 taquizoítos, respectivamente, para determinar la virulencia del aislamiento; se determinó el porcentaje de mortalidad y el tiempo de supervivencia para cada grupo. Posteriormente, se examinó el rendimiento y el factor de crecimiento en pases sucesivos en ratón.}

Extracción de ADN y prueba de PCR para el gen B1: a partir de los parásitos recuperados del cultivo en ratón, se realizó la extracción de ADN utilizando el estuche de purificación Wizard genomics $®$ (Promega, WI, USA) de acuerdo con las instrucciones del fabricante. Se amplificó el gen B1 específico de Toxoplasma, utilizando la metodología de PCR anidada descrita previamente (18). El proceso de amplificación se llevó a cabo en un termociclador Amplitron II (Thermolyne, IA, USA). En resumen, en la primera amplificación se emplearon los iniciadores: N1-GGAACTGCATCCGTTCATGAG y C1-TCTTTAAAGCGTTCGTGGTC. En Ia PCR anidada se utilizaron los iniciadores N2TGCATAGGTTGCCAGTCACTG y C2GGCGACCAATCTGCGAATACACC. Todos los iniciadores fueron sintetizados por Invitrogen (NY, USA). Para la primera amplificación del gen B1 se realizaron 40 ciclos, cada uno con temperatura de desnaturación de $94^{\circ} \mathrm{C}$ por 1 minuto, temperatura de anillamiento de $53^{\circ} \mathrm{C}$ por 1 minuto y temperatura de extensión de $72^{\circ} \mathrm{C}$ por 1 minuto. Para la segunda amplificación se realizaron 14 ciclos, cada uno con temperatura de desnaturación de $94^{\circ} \mathrm{C}$ por 1 minuto, temperatura de anillamiento de $53^{\circ} \mathrm{C}$ por 30 seg y temperatura de extensión de $72^{\circ} \mathrm{C}$ por $30 \mathrm{seg}$. El producto de amplificación se analizó por electroforesis en gel de agarosa al 2\% y tampón TAE 1X teñido con bromuro de etidio. El producto se observó en un transiluminador ultravioleta.

PCR-RFLP para el SAG2: para la determinación del tipo de linaje del aislamiento se realizó la amplificación de ambos extremos del gen SAG2. Se analizó el locus SAG2 amplificando separadamente los extremos 5' y 3' del gen por la técnica de PCR- RFLP de acuerdo con la técnica descrita previamente por Howe et al. (2). El extremo 5' del locus fue amplificado por una PCR estándar de 40 ciclos con los iniciadores F4-GCTACCTCGAACAGGAACAC y R4GCATCAACAACAGTCTTCGTTGC, a una temperatura de anillado de $65^{\circ} \mathrm{C}$. A los productos de amplificación resultantes se les realizó una segunda amplificación de 40 ciclos, con los iniciadores internos F2-GAAATGTTTCAGGTTGCTGC y R2-GCAAGAGCGAACTTGAACAC utilizando como molde $1 \mathrm{ml}$ del producto amplificado. Los extremos 3' fueron amplificados en un primer PCR con los iniciadores F3-TCTGTTCTCCGAAGTGACTCC y R3-TCAAAGCGTGCATTATCGC y para la segunda amplificación con F2- ATTCTCATGCCTCCGCTTC y R-AACGTTTCACGAAGGCACAC. Los iniciadores fueron sintetizados por Invitrogen (NY, USA). Los segmentos amplificados del extremo 5' fueron purificados a partir del gel de agarosa con Gene Clean (Bio 101, Inc. Vista, California) y digeridos con Sau3A1 (Gibco, USA) que reconoce y corta la secuencia palindrómica GATC. Los segmentos amplificados de 3' fueron digeridos con la enzima Hhal (Gibco, USA) que corta la secuencia palindrómica GCGC. La reacción para ambas enzimas se incubó a $37^{\circ} \mathrm{C}$ por 1 hora y se inactivó a $60^{\circ} \mathrm{C}$ por $10 \mathrm{~min}$. Los fragmentos obtenidos se analizaron por electroforesis en gel de agarosa al 2\%. Se utilizó como control de digestión ADN de las cepas RH 
(tipo I), Martin (tipo I), SQM (tipo II) y CEP (tipo III). La digestión del amplificado del segmento $5^{\prime}$ con Sau3AI distingue las cepas tipo III y produce un fragmento de menor tamaño lo cual permite diferenciar las cepas tipo III de las tipo I y de las tipo II. La digestión del amplificado 3' con Hhal corta segmentos que diferencian las cepas tipo II de las de los tipos I y III (2).

Análisis de microsatélites: los microsatélites son repeticiones cortas de 2 a 6 nucleótidos altamente polimórficos. Se analizaron seis microsatélites utilizando las técnicas previamente descritas (4). En resumen, se amplificaron por PCR cuatro microsatélites previamente publicados: TUB-2, W35487, TgM-A y N82375. Otros dos microsatélites se obtuvieron de sitios encontrados en secuencias EST relativamente poco polimórficas disponibles en ToxoDB: BM189462, BM17053. Estas dos últimas secuencias de EST permiten una buena detección de genotipos atípicos, es decir, definidos por alelos diferentes a aquéllos presentes en los tipos I, II O III, o por recombinación de alelos clásicos. Las secuencias de los iniciadores utilizados se muestran en el cuadro 1. Los cebadores se marcaron en el extremo 5 ' con fluoresceína (6-FAM o HEX) para determinar el tamaño de los productos de PCR con un secuenciador automático (Abiprism 310 collection 1.0, Applied Biosystems, Courtabœuf, Francia). La variación en el tamaño de los productos de la amplificación se analizaron utilizando el programa
GeneScan (version 2.1; Applied Biosystems, Francia).

\section{Resultados}

Cultivo celular y cultivo en ratón: a los cinco días se observaron formas compatibles con Toxoplasma en el cultivo de las células HT29, y demostraron el crecimiento in vitro de los parásitos. Los ratones inoculados con el aislamiento inicial murieron a los 11 días después de la inoculación y en el lavado peritoneal se encontraron formas compatibles con Toxoplasma por observación microscópica. A partir de este material se realizaron 16 pases sucesivos y el mantenimiento de parásitos por pase en ratón tuvo una duración de 6 meses después de los cuales se cerró el cultivo y se conservó hasta el presente una colección de parásitos almacenados en congelamiento a $-70^{\circ} \mathrm{C}$. La viabilidad poscongelamiento del aislamiento se confirmó realizando pases sucesivos en ratón con resultados exitosos.

Inmunofluorescencia: se encontró que los parásitos presentaron una fluorescencia verde manzana alrededor de la membrana del taquizoíto lo cual indica una reacción específica que no se observó en el control negativo.

$D L_{100}$ y mantenimiento de la virulencia: el promedio de vida del grupo de ratones inoculados con 10 taquizoítos fue de 11 días con un rango de 9 a 13 días. El grupo inoculado con 1.000

Cuadro 1. Marcadores de microsatélites, iniciadores y polimorfismo alélico.

\begin{tabular}{|c|c|c|c|}
\hline Marcador & Definición & Iniciadores 5'-3' & $\begin{array}{l}\text { Rango de tamaño } \\
\text { de los alelos }(p b)\end{array}$ \\
\hline TUB 2 & $\begin{array}{l}\text { Gen } \beta \text {-tubulina de taquizoíto } \\
\text { TgRHF }\end{array}$ & $\begin{array}{l}\text { F HEX-CCAAGTTCTTCCGTCATTTC } \\
\text { R CCTCATTGTAGAACACATTGAT }\end{array}$ & $122-126$ \\
\hline $\operatorname{Tg} M-A$ & $\begin{array}{l}\text { Gen miosina A de taquizoíto } \\
\text { TgRH }\end{array}$ & $\begin{array}{l}\text { F 6-FAM-CATGTCCCTGTCGGTTTCTC } \\
\text { R CGTAAATGCGGATGGAAACT }\end{array}$ & $115-123$ \\
\hline W35487 & $\begin{array}{l}\text { TgESTzy77d12.r1 de cADN de } \\
\text { taquizoíto TgRH }\end{array}$ & $\begin{array}{l}\text { F 6-FAM-TGCTGCGGTCTTTTCTCTTC } \\
\text { R AACATGCCGTTCCCTTCC }\end{array}$ & $95-101$ \\
\hline BM189462 & $\begin{array}{l}\text { TgESTzyb39d10.y1 de cADN } \\
\text { de taquizoíto TgRH }\end{array}$ & $\begin{array}{l}\text { F 6FAM TGGTCTTCACCCTTTCATCC } \\
\text { R CAAACAGAGGTTTTTCTTGGTG. }\end{array}$ & $108-123$ \\
\hline BM175053 & $\begin{array}{l}\text { TgESTzyb18b05.y1 de cADN } \\
\text { de taquizoíto TgRH }\end{array}$ & $\begin{array}{l}\text { F 6FAM TTAGTGGCCTCTGCTCTTGC } \\
\text { R ATGGAACGCAGGGAGTTCT. }\end{array}$ & $101-127$ \\
\hline$N 82375$ & $\begin{array}{l}\text { EST TgESTzy52d03.r1 de cADN } \\
\text { de taquizoíto TgRH }\end{array}$ & $\begin{array}{l}\text { F 6-FAM TGCGTGCTTGTCAGAGTTC } \\
\text { R GCGTCCTTGACATGCACAT }\end{array}$ & $105-131$ \\
\hline
\end{tabular}

F: forward primer, R: reverse primer 
taquizoítos tuvo un promedio de vida de 8,6 días con un rango 6 a 12 días. El grupo de ratones inoculado con 500.000 taquizoítos tuvo un promedio de vida de 7,5 días con un rango de 6-9 días (figura 1). La $\mathrm{DL}_{100}$ fue de 10 taquizoítos, característica de las cepas virulentas en ratón (grupo clonal I). En cuatro pases sucesivos utilizando inóculos de 500.000 taquizoítos, el promedio de vida fue de 8 días con un rango de 512 y el rendimiento osciló entre 30 a 70 millones de taquizoítos por ratón, lo cual indica que la virulencia de la cepa en ratón se mantiene después de varios pases.

Amplificación del gen B1 y detección de T. gondii por PCR: la presencia del parásito se confirmó por la amplificación del fragmento esperado de 97 pb el cual se visualizó en un gel de agarosa al $2 \%$ (figura 2 ).

\section{Genotipificación por PCR-RFLP del gen SAG2}

de Toxoplasma: la amplificación de los extremos 5' llevó a la obtención de un producto de 241 pb, mientras que la amplificación de los extremos 3' dio lugar a un producto de $221 \mathrm{pb}$. Como control positivo de la reacción se usó ADN de la cepa de referencia $\mathrm{RH}$. El patrón de digestión del aislamiento mostró que no hubo digestión, lo cual corresponde a un aislamiento del tipo clonal I, y que se mantuvieron los pesos esperados para cada fragmento (figura 3) (cuadro 2).

Análisis por microsatélites: el cuadro 3 resume los resultados de cada uno de los microsatélites amplificados para el aislamiento. Los datos confirmaron que se trata de una cepa del grupo clonal I ya que el tamaño de los alelos amplificados correspondió al rango esperado para este grupo. Para descartar una posible contaminación o cruce entre la cepa de referencia $\mathrm{RH}$ que se mantiene en el laboratorio del Centro de Investigaciones Biomédicas y el aislado, se compararon los microsatélites de ambas cepas y se confirmó que es una cepa diferente a la $\mathrm{RH}$ del laboratorio pues su genotipo mostró una diferencia en el tamaño del alelo de dos pares de bases para el marcador N82375 (figura 4).

\section{Discusión}

El conjunto de técnicas utilizadas permitió confirmar que el parásito obtenido en el niño con

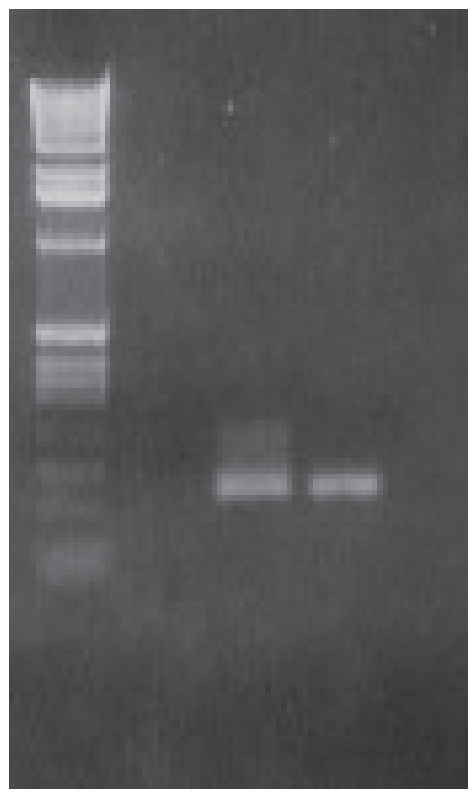

Figura 1. Amplificación por PCR del gen B1 específico de Toxoplasma gondii. Carril 1: marcador de peso molecular 1 kb ADN Ladder (Gibco BRL); carril 2: control negativo; carril 3: control positivo cepa RH; carril 4: cepa CIBMUQ /HDC. Se observa la amplificación de 2 fragmentos de 196 y 97 pb para el control positivo y un fragmento de $97 \mathrm{pb}$ para la cepa CIBMUQ /HDC. Los productos se visualizaron en un gel de agarosa al $1 \%$ teñidos con bromuro de etidio.

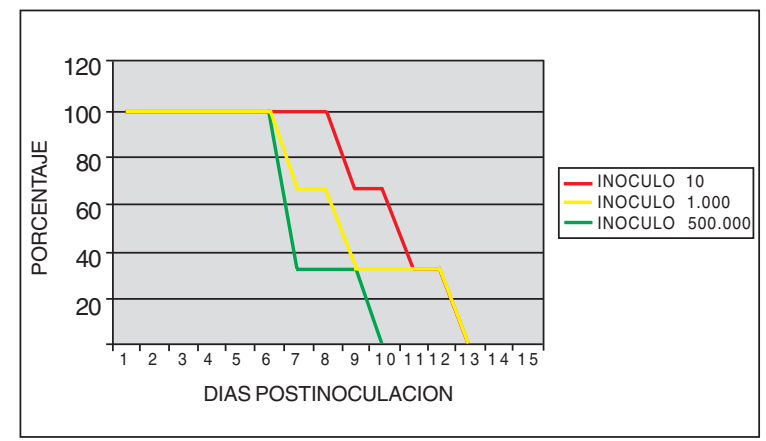

Figura 2. Análisis de supervivencia de la cepa CIBMUQ/ HDC en ratón. Se usaron tres grupos de tres ratones ICR, cada uno de ellos con diferentes inóculos de taquizoítos de la cepa CIBMUQ/HDC inoculados por vía intraperitoneal. La gráfica muestra el porcentaje de supervivencia en cada grupo por cada día posinoculación.

síntomas de toxoplasmosis congénita correspondía a T. gondii del grupo clonal I. Previamente se ha reportado que el grupo clonal I y algunas cepas atípicas se asocian con mayor 


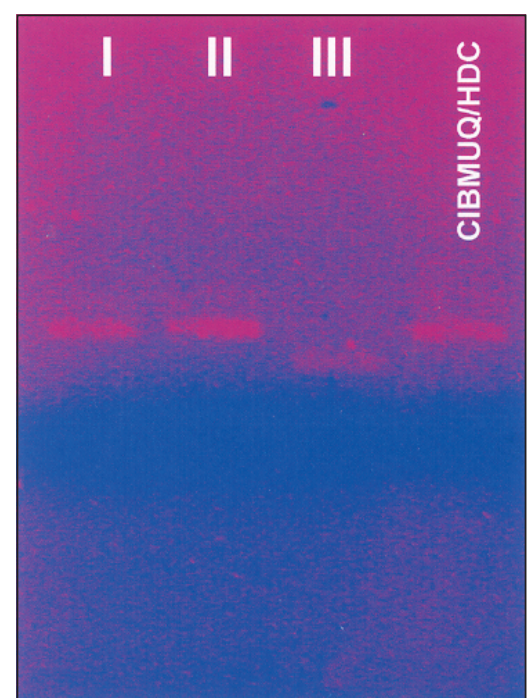

A
PB

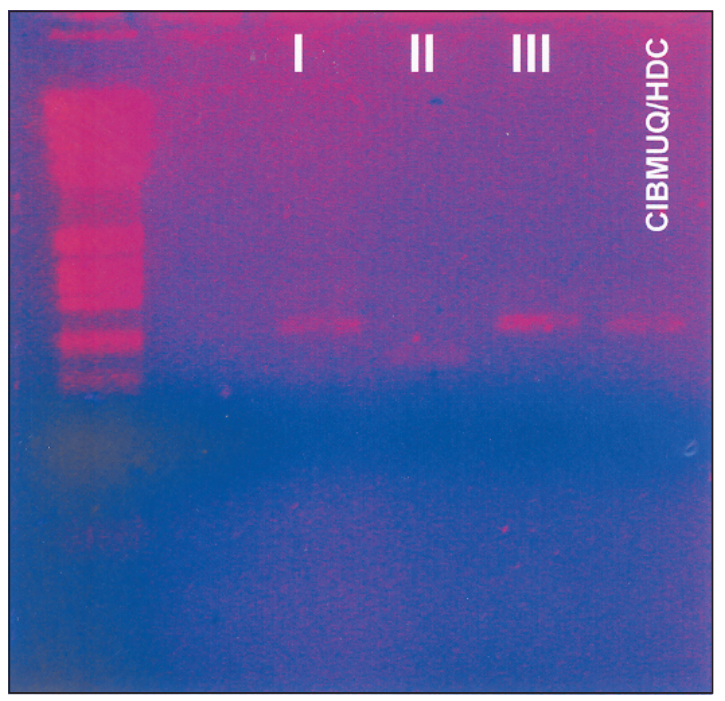

B

Figura 3. Genotipificación por PCR-RFLP del gen SAG2 de Toxoplasma. A) Amplificación del extremo 5' y análisis de restricción con la enzima Sau3AI. Se observa el patrón de restricción de los tipos clonales I (cepa RH), II (cepa SQM) y III (cepa CEP) y la ausencia de corte en el aislamiento CIBMUQ/HDC. B) Amplificación del extremo 3’y análisis de restricción con la enzima Hhal. Se observa el patrón de restricción de los tipos clonales I, II y III y la ausencia de corte en el aislamiento CIBMUQ/HDC, marcador de peso molecular (PM) de $1 \mathrm{~kb}$ ADN Ladder (Gibco BRL). Los productos se visualizaron en un gel de agarosa al $1 \%$ teñidos con bromuro de etidio.

frecuencia con casos graves de toxoplasmosis congénita, aunque el tipo Il es el más frecuentemente encontrado (19). Es interesante anotar que en los estudios realizados hasta el presente en Brasil y Argentina en animales predomina el grupo clonal I (19-21) pero no se conoce la frecuencia en los casos de toxoplasmosis congénita en Suramérica.

El presente trabajo permitió obtener una cepa aislada de un caso humano que crece bien en cultivo celular y en ratón y que puede ser utilizada por investigadores a nivel nacional e internacional, pues se conserva en el Centro de Investigaciones Biomédicas de la Universidad del Quindío (Colombia) y en el Laboratorio de Parasitología de Limoges (Francia). Las cepas de referencia son de utilidad para la comunidad científica dado que permiten su uso en experimentos que requieren conocer de manera segura y controlada las características del patógeno. En el caso del Toxoplasma, la cepa RH ha sido la cepa de referencia por excelencia; sin embargo, desde su aislamiento en 1939 hasta el presente se ha encontrado que los aislamientos de $\mathrm{RH}$ tienen variaciones considerables a nivel genético entre varios laboratorios (22). Idealmente, se debería tener un aislamiento que conserve las características iniciales que presentaba en el momento de su obtención de manera estable. De otra parte, para algunas comunidades científicas como la colombiana o latinoamericana en

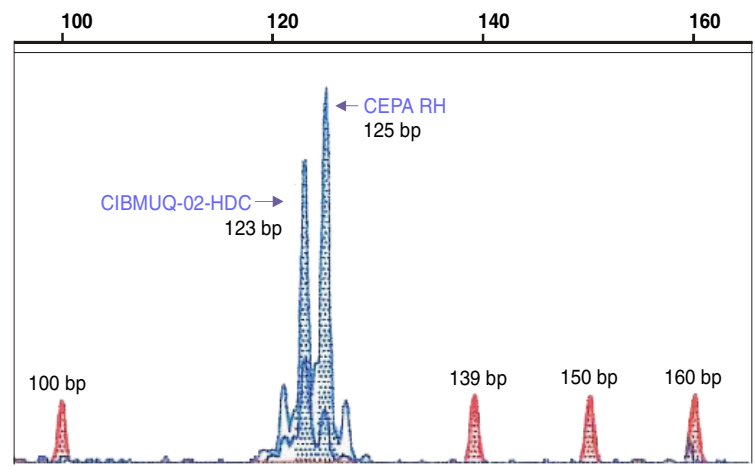

Figura 4. Comparación del tamaño del alelo para el marcador N82375 entre las cepas RH y CIBMUQ/HDC de Toxoplasma gondii. Se presentan los resultados del secuenciamiento automático (Abiprism 310, Francia) entre la cepa $\mathrm{RH}$ y CIBMUQ/HDC. Se observa la diferencia en un par de bases en el alelo N82375 entre ambas cepas. 
Cuadro 3. Análisis de microsatélites: tamaño de los fragmentos amplificados en la cepa CIBMUQ/HDC y tamaños de fragmentos esperados por grupo clonal.

\begin{tabular}{lccccc}
\hline Cepa & TUB-2 & W35487 & $\begin{array}{r}\text { Marcador } \\
\text { TgM-A }\end{array}$ & BM189462 & BM17053 \\
\hline CIBMUQ/HDC & 126 & 101 & 121 & 113 & 107 \\
Tipo I & 126 & 101 & 121 & 113 & 107 \\
Tipo II & 124 & 95 & 119 & 111 & 101 \\
Tipo III & 124 & 95 & 117 & 113 & 101 \\
\hline
\end{tabular}

ocasiones es difícil tener acceso a cepas de referencia debido a su costo y a la dificultad para su envío desde el exterior. La utilización potencial es amplia una vez se cuenta con un aislamiento bien caracterizado desde el punto de vista molecular, biológico e inmunológico. Entre los estudios en los que se puede utilizar se incluyen los de comparación de virulencia entre aislamientos y los ensayos experimentales para evaluar candidatos vacunales o medicamentos. Aún más, un aislamiento propio de la región de estudio que conserve las características singulares de la población en la cual se ha mantenido y que han permitido su evolución puede ser de importancia para establecer diferencias entre nichos ecológicos.

Se espera que los estudios de la variación intraespecie en Toxoplasma puedan suministrar claves sobre la existencia de factores de virulencia y su correlación con las formas clínicas (19) que mejoren los blancos terapéuticos. En conclusión se obtuvo un aislado colombiano de Toxoplasma gondii del tipo clonal I a partir de un caso de toxoplasmosis congénita que pudo ser caracterizado biológica y molecularmente de manera completa, lo cual permitirá su utilización como cepa de referencia.

\section{Agradecimientos}

Trabajo financiado por la Universidad del Quindio (Proyecto 184) y Colciencias (Proyecto código 11130412931)

\section{Referencias}

1. Wong SY, Remington J. Toxoplasmosis in pregnancy. Clin Infect Dis 1994;18:853-62.

2. Howe DK, Honore S, Derouin F, Sibley LD. Determination of genotypes of Toxoplasma gondii strains isolated from patients with Toxoplasmosis. J Clin Microbiol 1997;35:1411-14.
3. Fuentes I, Rubio JM, Ramirez C, Alvar J. Genotypic characterization of Toxoplasma gondii strains associated with human toxoplasmosis in Spain: Direct analysis from clinical samples. J Clin Microbiol 2001; 39:1566-70

4. Johnson AM. Speculation on possible life cycle for the clonal lineages in the genus Toxoplasma. Parasitol Today 1997;14:43-5.

5. Ajzenberg $D$, Bañuls AL, Tibayrenc $M$, Dardé $M L$. Microsatellite analysis of Toxoplasma gondii shows considerable polymorphism structured into two main clonal groups. Int J Parasitol 2002;32:27-38.

6. Darde $M L$, Bouteille $B$, Pestre Alexandre $M$. Isoenzyme analysis of Toxoplasma gondii isolates and the biological and epidemiological implications. J Parasitol 1992;78:786-94.

7. Sibley DL, Boothroyd JC. Virulent strains of Toxoplasma gondii comprise a single clonal lineage. Nature 1992;359:82-5.

8. Ajioka JW, Fitzpatrick JM, Reitter CP. Toxoplasma gondii genomics: shedding light on pathogenesis and chemotherapy. Expert Rev Mol Med 2001;20:1-19.

9. Kim K, Weiss L. Toxoplasma: the model apicomplexan. Int J Parasitol 2004;34:423-32.

10. Howe DK, Sibley LD. Toxoplasma gondii comprises three clonal lineages: Correlation of parasite genotype with human disease. J Infect Dis 1995;172:1561-6.

11. Gómez JE, Castaño JC, Rios MP, Montoya MT. Toxoplasmosis congénita e hidranencefalia. Acta Med Col 1992; 17:457-8.

12. Bambirra EA, Pitella JE, Rezende M. Toxoplasmosis and hydranencephaly. Lancet 1982;306:112-3.

13. Castaño JC, Gómez JE, Duque AM. Toxoplasmosis Ocular en el Quindío: Características clínicas. Biomédica 1991;11:121.

14. Silveira C, Belfort R, Burnier M, Nussenblatt R. Acquired Toxoplasmic retinochoroiditis in families. Am J Opthalmol 1988;106:362-4.

15. Carme B, Bissuel F, Ajzenberg D, Bouyne R, Aznar C, Demar M. et al. Severe acquired toxoplasmosis in immunocompetent adult patients in French Guiana. J Clin Microbiol 2002;40:4037-44. 
16. Brindley PJ, Gazzinelli RT, Denkers EY, Davis SW, Dubey JP, Belfort R Jr. et al. Differentiation of Toxoplasma gondii from closely related Coccidia by riboprint analysis and a surface antigen gene polymerase chain reaction. Am J Trop Med Hyg 1993; 48:447-56

17. Castaño -Osorio JC, Martínez AR, Marcel R, Sarracent J. Producción de anticuerpos monoclonales contra las proteínas mayoritarias de la membrana P30 (SAG1) y P22 (SAG2) de Toxoplasma gondii. Rev Investigaciones Univ Quindio 2003;4:97-106.

18. Ponce NC, Gómez JE. Estandarización y validación clínica de la prueba de reacción en cadena de la polimerasa (PCR) para diagnóstico de toxoplasmosis cerebral en pacientes infectados por el VIH. Infectio 2003;7:8-14.

19. Dubey JP, Graham DH, Blackston CR, Lehmann T, Gennari SM, Ragozo, AM. et al. Biological and genetic characterisation of Toxoplasma gondii isolates from chickens (Gallus domesticus) from Sao Paulo, Brazil: unexpected findings. Int J Parasitol. 2002;32, 99-105.

20. Dubey JP, Graham, DH, Da Silva DS, Lehmann T, Bahia-Oliveira LM. Toxoplasma gondii isolates of freeranging chickens from Rio de Janeiro, Brazil: mouse mortality, genotype and oocyst shedding by cats. J Parasitol 2003;89, 851-53.

21. Dubey JP, Navarro IT, Graham DH, Dahl E, Freire $\mathrm{RL}$, Prudencio LB. et al. Characterization of Toxoplasma gondii isolates from free range chickens from Parana, Brazil. Vet. Parasitol 2003;117, 229-34.

22. Ajzenberg D, Cogne $\mathrm{N}$, Paris L, Bessieres $\mathrm{MH}$, Thulliez P, Fillisetti D. et al. Genotype of 86 Toxoplasma gondii isolates associated with human congenital toxoplasmosis and correlation with clinical findings. J Infect Dis 2002;186:684-9. 